\title{
An Approach Multi-Agent with the Best Practice of ITIL, to Maintain the Operability of a Data Warehouse
}

\author{
Aziza CHAKIR \\ Systems Architecture Team, \\ Laboratory of Informatics, \\ System and Renewable Energy \\ Hassan II University - ENSEM \\ Casablanca, Morocco
}

\author{
Hicham MEDROMI \\ Systems Architecture Team, \\ Laboratory of Informatics, \\ System and Renewable Energy \\ Hassan II University - ENSEM \\ Casablanca, Morocco
}

\author{
Adil SAYOUTI \\ Systems Architecture Team, \\ Laboratory of Informatics, \\ System and Renewable Energy \\ Hassan II University - ENSEM, \\ Royal Naval College \\ Casablanca, Morocco
}

\begin{abstract}
The data warehouse is not a new practice in the IT world, all the domains which have data can make a decision system, data warehouse, to exploit well the generated knowledge we have to maintain the good conditions to have a good decision making. By the application of the best practice of ITIL, we limit the risks and the malfunction of a data warehouse, and by the addition of a layer which treats the validity of the quality of the data, the integration of the data and the mapping of the data, we guarantee the reliability of the information integrated into a data warehouse.
\end{abstract}

The objective of this paper is to propose an approach maintain operability of a data warehouse in the good conditions, using multi-agent systems and best practices of ITIL.

\section{General Terms}

Data warehouse, governance.

\section{Keywords}

Data warehouse, ITIL, multi-agents systems (MAS), governance, constraints of the data warehouse, Information system.

\section{INTRODUCTION}

The decision system, the data warehouse, is invented to help a company to reach their goals and to answer the stakes in the politics of management of the company.

The data warehouse is a database dedicated to the storage of all the data so as to extract the knowledge from it and so favor the decision-making and the decision-making analysis. The data warehouse is the collection, the consolidation, and the modeling of the data of production of a company to extract the most relevant information. For that purpose, it is necessary to adopt an approach of construction which allows to minimize the risks which can impact on the decisionmaking chain to succeed always a complete and completely integrated system.

Yet, the erroneous entry of data can engender a bad decision. Indeed the added value of a data warehouse holds the quality of the data which it contains. It is advisable to feed it only with reliable and coherent enough data.

To have and maintain a data warehouse in operational condition, we proposed an architecture which implements the processes of the best practice of ITIL [5] [13], which presents an interaction with the users and with the database, and other processes which treats the quality of the data by using the multi-agents systems (MAS).

In this optics, it would be necessary to ask the question on the contribution of ITIL and on the contribution of the governance in the maintenance of the data warehouse in the good conditions.

The choice of the best practice of ITIL [1] [2] [11] [12] is inspired by the made that this reference approaches all the domains of the governance of information systems. it update continues and it support with the other references such as Cobit, ISO 27000, PMBOK and regulations such as SOX, solvency Basel II, guided our choice. The governance of information systems is a set of process allowing to pilot the information systems of an organization which is a common point with the MAS, the management by process [8]. This management assures a better management of information technologies.

\section{PROBLEMATIC}

The data warehouse is implemented to help organizations to have a real image on the objectives realized, to plan and reach it in the future. This data warehouse can engender bad decisions if the analysis is less deep or the entrance of data is erroneous and it can also be subject of bugs bound to the bad human manipulation which impacts on the time of answer of a request.

To remedy these inadequacies, we proposed architecture which treats the quality of input data, and which integrates the best practice of ITIL and the multi-agents systems (MAS).

\subsection{Data warehouse}

The data used in the decision-making analysis are stored to establish a database, it is the same database which bears the name of data warehouse. These data are organized by subject, integrated, historicized and not volatile. The data warehouse isn't only a sample copy of the data of the bases of production, and it is necessary to not forget the transformation, the cleaning and the storage of these data which are assured by the tools of ETL (Extraction, Transformation and Loading). The following plan presents the stages of supply of a data warehouse. 


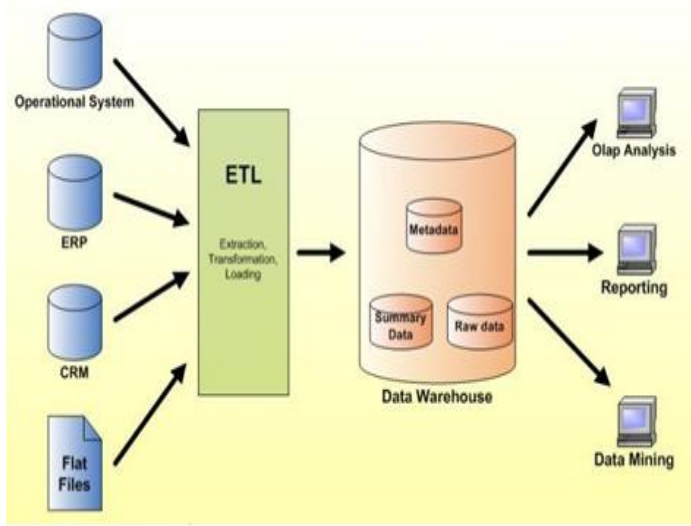

Fig 1: the stages of supply of a data warehouse [14]

The knowledge generated by the data warehouse is used for:

- Manager and/or provide.

- Estimate the risks.

- Make a study of the behavior of the customers to allow companies to define strategies to target their customer.

\subsection{Constraints of data warehouse}

The data warehouse isn't easy to set up and to maintain in operational condition. In this part we are going to treat two axes which influence the smooth running of a data warehouse [16].

- The validity of the data

- The management of the changes

\subsubsection{The validity of the data}

Data warehouse is a solution for the business people to make decisions and the true action. The use of this science without making sure of the validity of the data and even of their volume can cause a not appropriate implementation.

The act of measuring the evolution of a company in terms of capacity of the data warehouse to satisfy the waiting of their users. Hence the need to address quality, which must be before the development of a data warehouse.

The external databases and the intern databases allow to approach the totality of the activity of the company. These external data put in most of the cases a major problem which concerns the methods of seizure and of treatment what will produce erroneous results and bad decisions by the executive group of a company.

\subsubsection{The management of the changes}

A data warehouse evolves inevitably in case of evolution of a company (for example the creation of new services or new need for a user). Before any change, it is necessary to make sure that there are no negative effects on the functioning of the system of the company.

The possibilities offered by a data warehouse risk not to be exploited any more, if the new version of data warehouse causes changes for the users or the bugs during their use.

The ideal is to maintain a good exchange with the users of the data warehouse to anticipate its needs.

\section{METHODOLOGY}

The proposed solution consists in adding layers to a data warehouse to assure their functioning in a correct way:

- Layer to make sure of the validity of the data by using multi-agents systems.

- Layer to govern well the data warehouse with best practice Of ITIL and multi-agents systems [10] [15].

\subsection{The validity of the data}

The quality of the data influences the decision making, the first part of the proposed approach assures the quality of the data before integrating them into the data warehouse. This approach proposes three sub layers to process the data and every sub layer is endowed with a system multi-agent:

- A sub layer which implements a process of validation of the data.

- A sub layer which assures the integrity of the data before storing them in the data warehouse.

- A sub layer which facilitates the mapping of the entrantes data towards the destination.

The following plan represents three sub-layers of the treatment of the sources of the data:

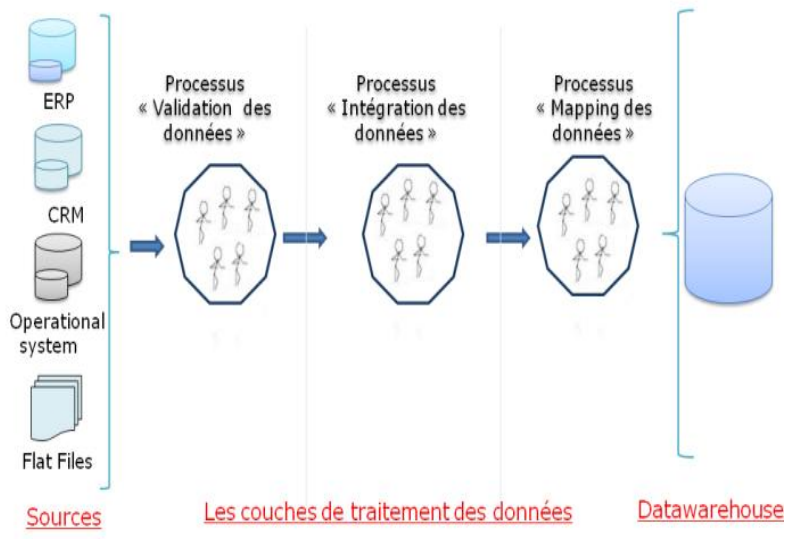

Fig 2: The three sub-layers of the treatment of the sources of the data

\subsubsection{Process of the validation of the data}

The analysis and the examination of the data are two necessary actions to assure the structure of the data before their storing in the data warehouse, to maintain the quality of these data, to avoid the false suppositions and the unforeseen gaps by the users of the data warehouse.

To avoid such a situation, the process of the validation of the data is going to allow us to verify the validity of the data and to establish databases to integrate data of high quality into the data warehouse.

The process of the validation of the data is extremely useful to profile the data before their storage in the data warehouse while avoiding the problems and the possible rectifications during the development of the data warehouse.

The data sources can be:

- Absent or partially absent,

- Erroneous,

- Made obsolete, 
- Weak,

The following plan represents the functioning of the process "validation of the quality of the data":

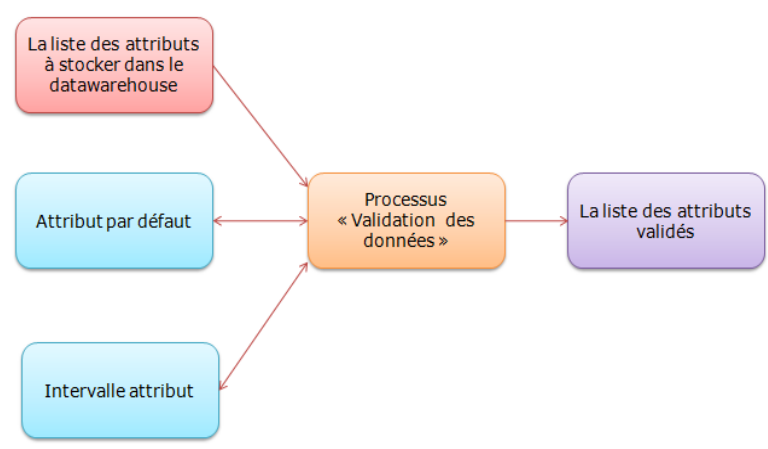

Fig 3 : The functioning of the process validation of the quality of the data

\subsubsection{Process of the integration of the data}

The second process is "process of integration of the data" which assures that the format of the data to be stored in the data warehouse is correct to standardize the format of the data and reduce the transformations of the data from a format to another one.

The following plan represents the functioning of the process of integration of the data:

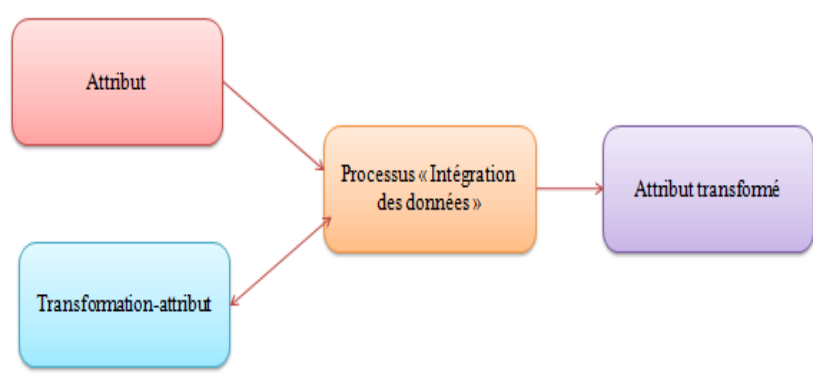

Fig 4 : The functioning of the process of integration of the data

\subsubsection{Process of mapping of the data}

The third process is "the process of mapping of the data" that assures and which facilitates the mapping of the data sources towards the destination, the data warehouse. The following plan represents the functioning of the process "mapping of the data":

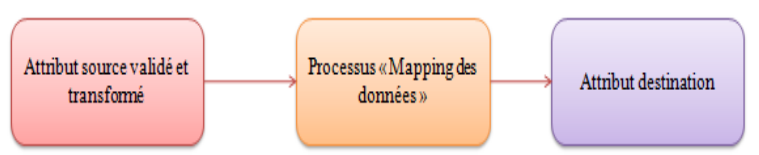

Fig 5 : The functioning of the process "mapping of the data"

The architecture illustrated in the figure 6 presents the first layer which allows to treat the data to ensure the good functioning of any data warehouse based on multi-agent systems.

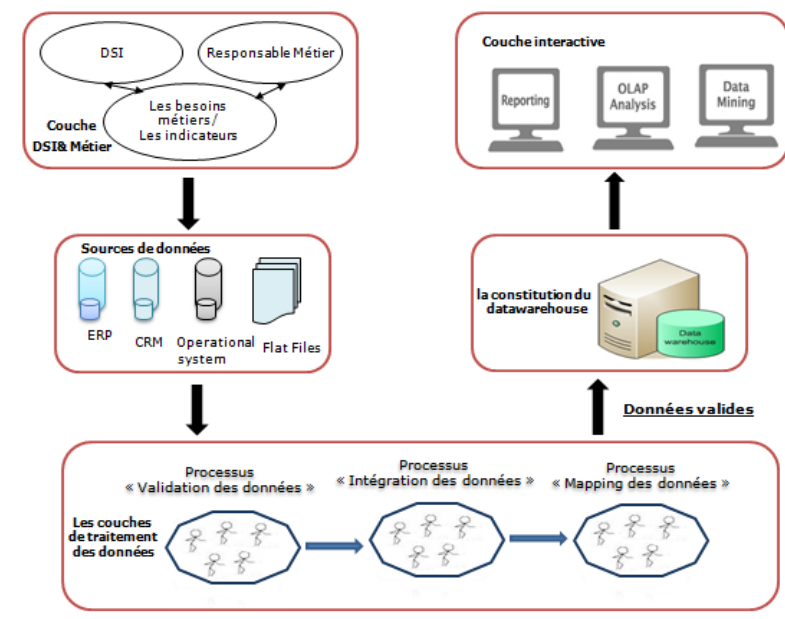

Fig 6: The first layer which ensures the validity of the data

\subsection{The governance of a data warehouse with the best practice of ITIL}

The addition of a layer endowed with the best practice of ITIL and with the multi-agents system is going to maintain the smooth running of the data warehouse, it is going to minimize the negative impact of every type of dysfunction on the decision-making chain.

\subsubsection{The governance}

The governance of information systems [6] [9] is a procedure of regulation which defines the way organizations are capable of aligning the IT strategy with the corporate strategy, and keep the business on track to achieve their goals and implement the good manners to measure the performance.

It is more and more considered as a sequence of process capable of assuring the stability of an organization and of reaching it goals by following a well defined communication policy.

The governance of information systems is a challenge of management taking into account the culture of the company; it has five pillars which are:

- The strategic alignment: the alignment of the strategy information system with the strategy business to cascade the strategy and the objectives of the company.

- The creation of the value: the financial control of the information system.

- The risk management: focus on the control which has to apply and adopt for the information system.

- The resource management: the assistance of the implementation of the strategy, and the objectives by supplying the necessary organizational structures.

- The measure of performance: the accroissance of the performance of the information system by report needs customers. 


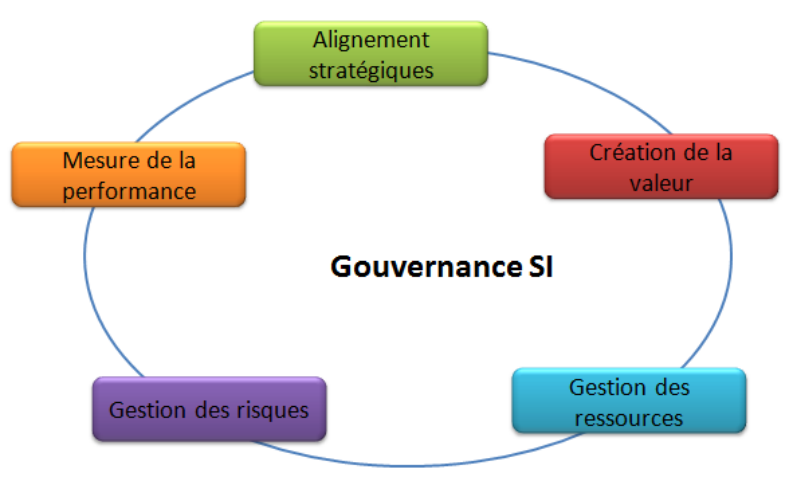

Fig 7: Five pillars of the governance of information system

\section{2 .2 ITIL}

ITIL (Information Technology Infrastructure Library) [7] [11] is a collection of best practice for the supply of IT services. it contributes to improve the efficiency and to reduce the risks.

ITIL [3] supplies a methodological approach consisting of a series of modules to help companies and organizations to improve the use of the computing resources.

ITIL consists of five modules, the modules are going to manage an IT service and to align IT services on the objectives of a company.

Five modules of ITIL are the following ones:

- Strategy of the services.

- Conception of the services.

- Transition of the services.

- Exploitation of the services.

- The continuous improvement of the services.

The plan below present five aspects of the best practice of ITIL.

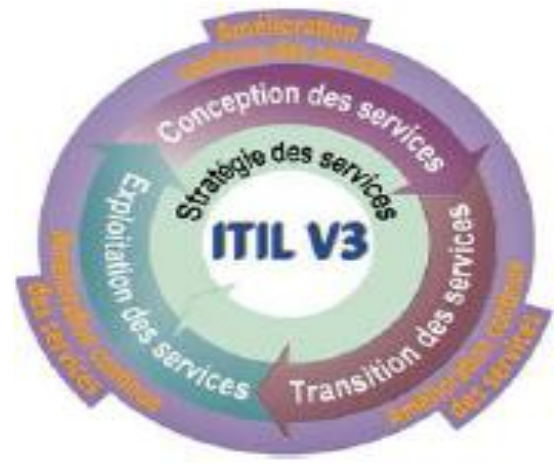

Fig 8: ITIL-life cycle of the services

\subsubsection{Support of IT services}

The best practice of ITIL presents all the aspects to make sure that the domain of the information technology can take care of the IT applications which supply functions to the company by guaranteeing the continuity, the availability and the quality of service to the users [15].
The actual support for IT services by applying the best practice of ITIL is assured through the following six processes:

- Center of services

- Management of the configurations

- Management of the change

- Management of the stakes in production

- Management of the incidents

- Management of the problems

\subsubsection{Supply of IT services}

To follow and to improve the quality of the applications of the information system on the levels of customer service, ITIL proposes the following five processes:

- Management of the levels of service

- Management of the capacity

- Management of the availability

- Management of the continuity of service

- Financial management of the services

\subsubsection{ITIL and the governance of a data} warehouse

An effective governance is the key of the success of the data warehousing. The data warehouse gave to organization a lot of advantages, in particular by supplying a unique version of the truth, a better data analysis, a reduction of time of answering.

The governance also has to approach the operational problems, such as the problems to access to data by the end users. The governance of the decision making systems requires a defense of the data warehouse so that it works correctly.

The governance of the data warehouse with the best practice of ITIL is conceived to keep the good running of it by maintaining that supplies a service of high quality to his customers and by assuring a good management of the problems, the infrastructure, the broadcasting of the information, and the level of supplied service. We are going to treat the processes of ITIL which we are going to use to maintain the operability of a data warehouse [17].

- Center of service

- The management of the incidents

- The management of the problems

- The management of the change

- The management of the levels of services

- The management of the availability

- The management of the continuity

- The management of the stakes in production

The architecture illustrated in the figure 9 presents the second layer which provides the governance of data warehouse based on the best practices of ITIL and the multi-agent systems, this architecture will allow users of the data warehouse to improve the quality of services rendered, optimize resource management and cost control. 


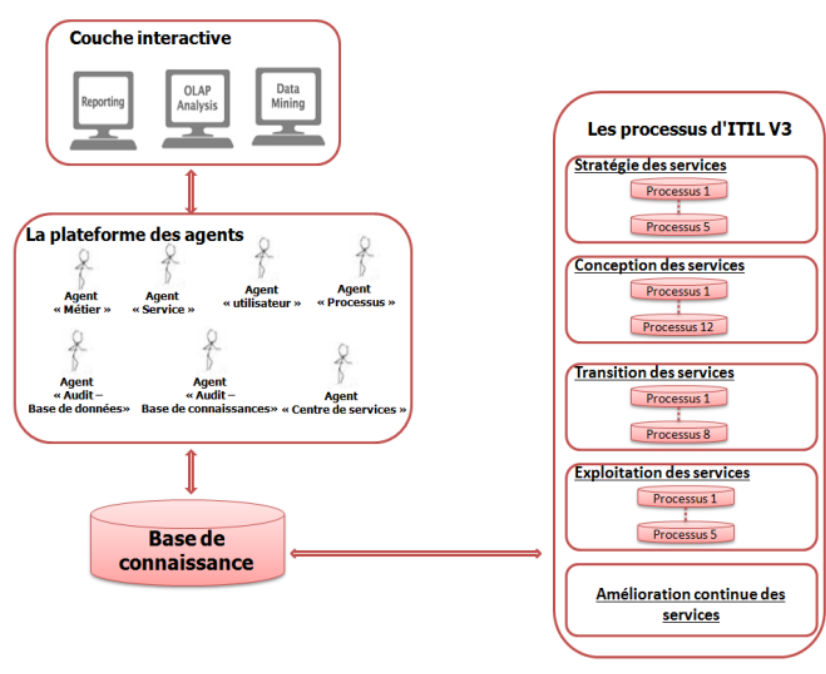

Fig 9: The second layer which ensures the governance of the data warehouse

\section{THE GLOBAL ARCHITECTURE}

The control of the best practice of ITIL by the professionals can improve the organization during the control, this is the raison of the necessity of having an IT service of more reliable control to manage to identify its problems seen to decrease the disturbances by the fact of a dysfunction of the services TI in one begun, and it can be made by the governance of information systems and to estimate the maturity of says systems.

The architecture illustrated in the figure 10 presents the first and the second layer that allows to set up treatments that can improve the weaknesses that the objective is to ensure the proper functioning of any data warehouse based on best practices ITIL and multi-agent systems.

This architecture is also going to allow the users of the data warehouse to improve the quality of services provided, to optimize the resource management and to check the costs.

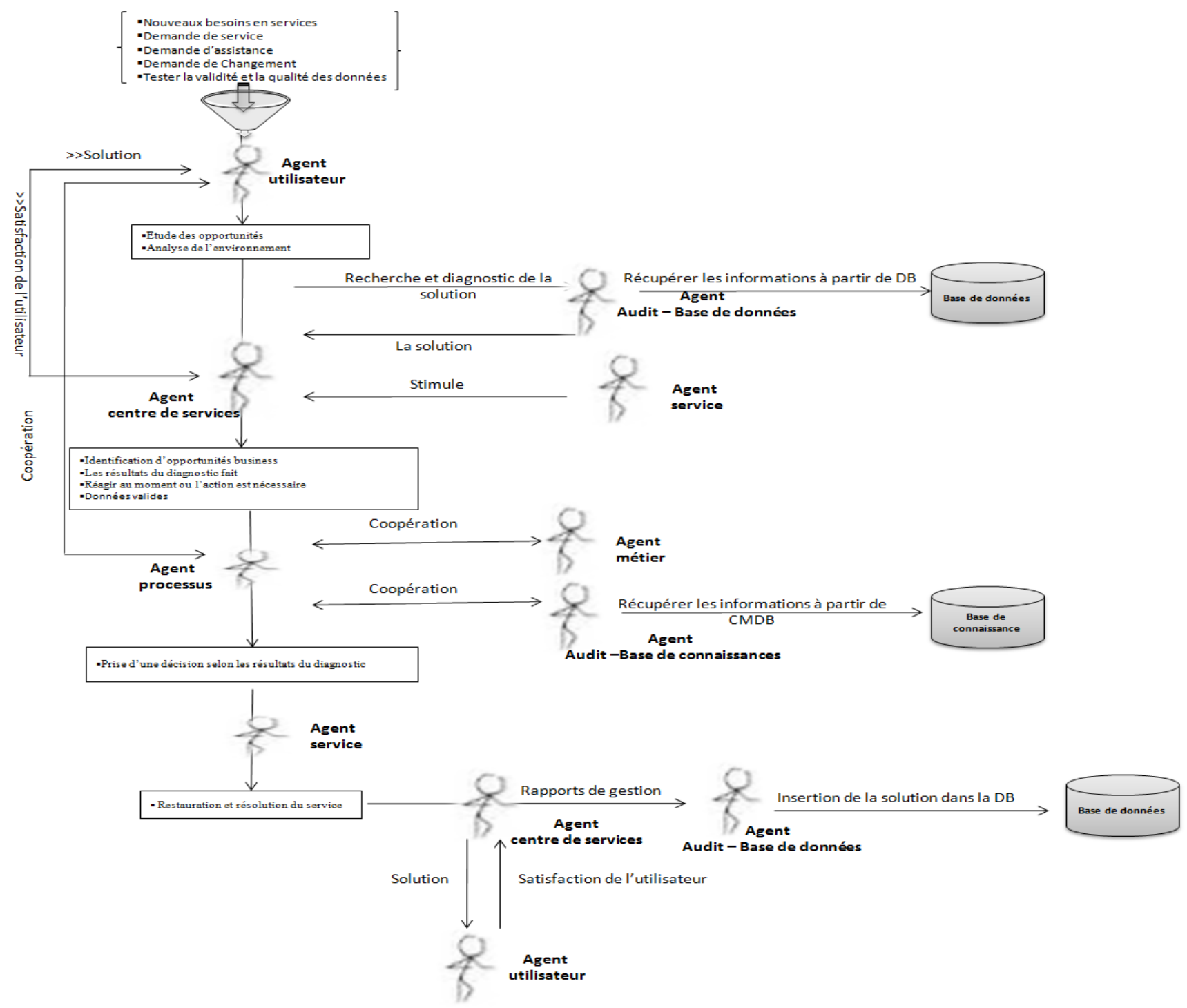

Fig 10: Modeling of the first and second layer which ensures the good functioning of data warehouse 
The modeling of the proposed solution is based on the principle of the multi-agents systems which is: "everybody has to cooperate to reach the same goal". The proposed architecture consists of following agents:

- Agent "user": reactive agent who reacts when the action is necessary.

- Agent "center of services": cognitive agent can communicate, intervene and control the agent service, the agent process and the agent knowledge base. This agent reacts according to the results generated by the agent "audit database"

- Agent "service": reactive agent who reacts during the intervention of the agent "center of services" to accommodate agents process to build a space for their activities.

- Agent "process": cognitive and reactive agent, hybrid agent, by cooperation with the agent "business" and the agent user it makes a decision when it was stimulate by the agent "center of services".

- Agent "business": reactive agent, according to the situations, it interacts with the agent "process".

- Agent "knowledge base": cognitive agent who has for objective to recover the information from the knowledge base.

- Agent "audit database": reactive agent, who has for objective to recover the information from the database when it was stimulate by the agent "center of services".

\section{CONCLUSION}

The knowledge generated by a data warehouse is a strong source for the daily management and for the decision-making support. For that purpose, it is necessary to assure the reliability of the information supplied by the data warehouse and the good quality of the service provided to the users of the data warehouse.

The proposed solution presents two layers, the first layer ensure the validity of the data before their integrating into a data warehouse by using the multi-agent systems and the second layer which provides the governance of data warehouse based on the best practices of ITIL and the multiagent systems. It suggests tactics for all the blocking situations, to maintain the good conditions of the functioning of the data warehouse.

We plan the implementation of a generic platform which translates the proposed method.

\section{REFERENCES}

[1] Christian Dumont, "Gestion des services informatiques, une introduction basée sur l'ITIL".
[2] Steigmeier Alexandre, "Comment articuler les differentes norms et methodes".

[3] Aziza Chakir; Hicham Medromi; Adil Sayouti, "La gouvernance du système d'information à base des bonnes pratiques d'ITIL V3“, JDTIC NOVEMBRE 2012.

[4] Aziza Chakir; Hicham Medromi; Adil Sayouti, "Une approche multi-agents pour la gouvernance d'un data warehouse à base des bonnes pratiques d'ITIL“, JDSIRT 2013.

[5] Hamilton Mann, Jean-Marc Bellet, et Marc Lamy, “ Améliorer la qualité des services : Avec la Gestion des Problèmes ITIL".

[6] Morley+Al, “ Processus métiers et S.I. - Gouvernance, management, modélisation - 3e édition".

[7] Pascal Delbrayelle, http://www.itilfrance.com

[8] Jamal Skiti et Hicham Medromi, "Nouvelle Méthodologie de la Gouverance des Technologies de l'information à base du Système Multi-agent".

[9] Jamal Skiti et Hicham Medromi, “ La Gouverance des Technologies de l'Information à base du Système Multiagent et le référentiel COBIT".

[10] Bruno Claudepierre, “ Conceptualisation de la Gouvernance des Systèmes d'Information, Structure et Démarche pour la Construction des Systèmes d'Information de Gouvernance ", 10 décembre 2010

[11] Nicolas Dewaele, “ L'ITIL : Un référentiel pour la qualité des systèmes d'information ", 23 mars 2011

[12] Groupe DEVOTEAM, “Enquête internationale ITIL et la performance en entreprise 2010 "

[13] Tariq Rahim Soomro et Hasan Yousef Wahba, " Role of Information Technology Infrastructure Library in Data Warehouses ",2011

[14] Cécile Favre, Fadila Bentayeb et Omar Boussaid, "Maintenance de charge pour l'optimisation des entrepôts de données évolutifs : aide à l'administrateur"

[15] Yves B.Desfossés , Claude Y.Laporte , Alain April et Nabil Berrhouma, "Méthode d'amélioration des services de TI, basée sur ITIL, dans les entreprises québécoises ", septembre 2008

[16] Maxime Poletto, “ L’informatique décisionnelle-Thèse Professionnelle”, 01 juin 2012

[17] Aziza Chakir; Hicham Medromi; Adil Sayouti,"actions for data warehouse success", Journal - IJACSA 2013 Vol. 4, No.8, August 2013 